\title{
SIMULATING THE VOICE BLOCKING PROBABILITY, PACKET LOSS PROBABILITY AND PACKET DELAY FOR GSM/GPRS NETWORK
}

\author{
Dr. Osama El Ghandour \\ Electronics \& Communications and Computer Engineering \\ Department, Helwan University, Cairo, Egypt \\ osamaghn@hotmail.com
}

(Received September 18, 2005 Accepted November 30, 2005)

\begin{abstract}
The field of wireless mobile networking has advanced greatly over the last decade. Different protocols and technologies are in place today to provide wireless and mobility communications in various environments.

This paper uses an analytical approach for modeling the mobility effect as well as the data traffic load on the overall system performance in GSM General Packet Radio Service (GPRS) network.

An integrated voice/data wireless system with finite buffer for data traffic has been considered as in [1] and based on decomposition of system behavior into short-term and long-term behavior techniques that were introduced in [2]. We used a simplified analytical model to study some performance keys that enable us to evaluate the overall performance in GPRS network and to study how the data services affect the main performance of the GSM network and what is the limit of offered load intensity and mobility that can not be exceeded in order to get an accepted system performance.
\end{abstract}

KEYWORDS: General Packet Radio Service (GPRS), QoS, Delay, Performance, Mobility, Markov chain, handoff.

\section{INTRODUCTION}

GPRS has been standardized by the ETSI as part of the GSM phase 2 + development. It represents the first implementation of packet switching within GSM, which is essentially a circuit-switched technology.

By adding GPRS functionality to the existing GSM network, operators can give their subscribers resource-efficient wireless access to external Internet protocol-based networks, such as the Internet and corporate intranets. The basic idea of GPRS is to provide a packet-switched bearer service in a GSM network. As impressively demonstrated by the Internet, packet-switched networks make more efficient use of the resources for bursty data applications and provide more flexibility in general [3].

Voice and data integration in wireless networks has been recently investigated by wireless research community. An integrated voice/data wireless system with finite 
buffer for data traffic has been considered in [4], where the system is described by a two-dimensional Markov chain, and then the balance equations were given which we used to find the interesting performance parameters numerically.

In this paper, we focus on the performance of GPRS data service with buffering and dedicated channels for data traffic while we consider the effect of reneging data packets due to the corresponding user handoff where the customer abandons the system before receiving service. We consider the effect of handoffs for both voice and data traffic.

The paper is organized as follows. An explanation of the system model is presented in Section 2 with its assumptions then numerical results are presented in Section 3; finally, Section 4 concludes the paper.

\section{SYSTEM MODEL}

The system under consideration is a GSM/GPRS network. Figure 1 shows the base station architecture in cell $\mathrm{k}$ with ck channels, where $\mathrm{dk}$ channels are dedicated to GPRS data traffic and the rest, (ck - dk) channels, are shared by voice and data traffic. In the shared part, voice traffic has priority over data traffic and can preempt data traffic [5].

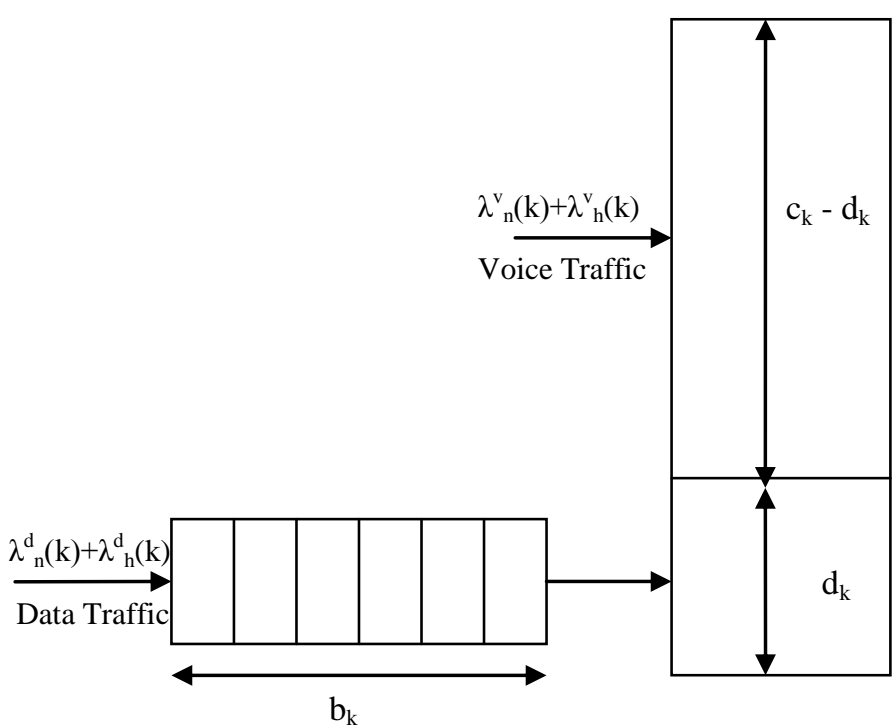

Fig. 1: Base station Architecture [5].

In this model, if there is no free channel upon initiating new data resource request, the request will be queued in a finite buffer to be served later according to FIFO scheduling. If a mobile station hands off to a neighboring cell, all of its associated requests for packet transmission which are waiting in queue will be immediately removed from the queue and forwarded to the destination cell for service. We assume that packet handoff cannot happen during the actual packet transmission due to the 
short length of data packets. If such an event happens at transmission time, it is the responsibility of lower layer protocols to assure the correct packet delivery.

Some assumptions and features of the previous model that introduced in [2] \& [5] are stated below:

1) The new voice call and data packet arrivals into cell $\mathrm{k}$ are Poisson distributed with rates $\lambda^{\mathrm{v}}{ }_{\mathrm{n}}(\mathrm{k})$ and $\lambda_{\mathrm{n}}^{\mathrm{d}}(\mathrm{k})$.

2) The residence time of a mobile station in cell $\mathrm{k}$ is assumed to be exponentially distributed with means $1 / \eta^{\mathrm{v}}{ }_{\mathrm{k}}$ and $1 / \eta^{\mathrm{d}}{ }_{\mathrm{k}}$ for voice and data, respectively.

3) The handoff call arrivals into cell $\mathrm{k}$ are assumed to be Poisson distributed with rates $\lambda^{\mathrm{v}}{ }_{\mathrm{h}}(\mathrm{k})$ and $\lambda_{{ }_{\mathrm{h}}}^{\mathrm{d}}(\mathrm{k})$.

4) The transmission time of a GPRS packet in cell $\mathrm{k}$ (or service time) is assumed to be exponentially distributed with mean $1 / \mu_{\mathrm{d}}$ Queued messages are served according to FIFO scheduling. Whereas the call holding time of a voice call is assumed to be exponentially distributed with mean $1 / \mu_{\mathrm{v}}$.

5) Define the mobility factor $(\alpha)$ to be the ratio of the mean service (or call holding) time to the mean residence time, i.e., $\alpha^{\mathrm{v}}{ }_{\mathrm{k}}=\eta_{{ }_{\mathrm{k}}}^{\mathrm{v}} / \mu^{\mathrm{v}}{ }_{\mathrm{k}}$ and $\alpha_{\mathrm{k}}^{\mathrm{d}}=\eta^{\mathrm{d}}{ }_{\mathrm{k}} / \mu^{\mathrm{d}}{ }_{\mathrm{k}}$.

6) A finite buffer with capacity $b_{k}$ packets is provided in each cell $k$ for GPRS packets only.

\section{ANALYTICAL MODEL}

The advantage of the quasi-stationary behavior of the data queuing process was used in [2] to get an approximate evaluation of the performance of the data service in GPRS systems as the mean holding time of voice calls is much larger than the mean service time of the data packets, where the voice calls evolve slowly compared to the data buffer dynamics. Then the probability vector of the Markov chain that describes the number of active voice calls in cell $\mathrm{k}$ as was introduced in [5].

$$
p_{k}(i)=\frac{1}{i !} \quad \frac{\lambda_{n}^{v}(k)+\lambda_{h}^{v}(k)}{\mu_{k}^{v}+\eta_{k}^{v}}{ }^{v}{ }^{i} p_{k}(0) \quad 1 \leq i \leq c_{k}-d_{k}
$$

Where

$$
p_{k}(0)=\left[1+\sum_{i=1}^{c k-d k} \frac{1}{i !} \quad \begin{array}{c}
\lambda_{n}^{v}(k)+\lambda^{v}{ }_{h}(k) \\
\mu_{k}^{v}+\eta_{k}^{v}
\end{array}\right.
$$

Simply the voice blocking probability can be given by

$$
\mathrm{B}_{\mathrm{k}}=\mathrm{p}_{\mathrm{k}}\left(\mathrm{c}_{\mathrm{k}}-\mathrm{d}_{\mathrm{k}}\right)
$$

To verify this analytical result we develop a MATLAB program to check the equation (3) and see how the voice blocking probability varies with the mobility factor for different values of offered voice load as shown in figure 2. 


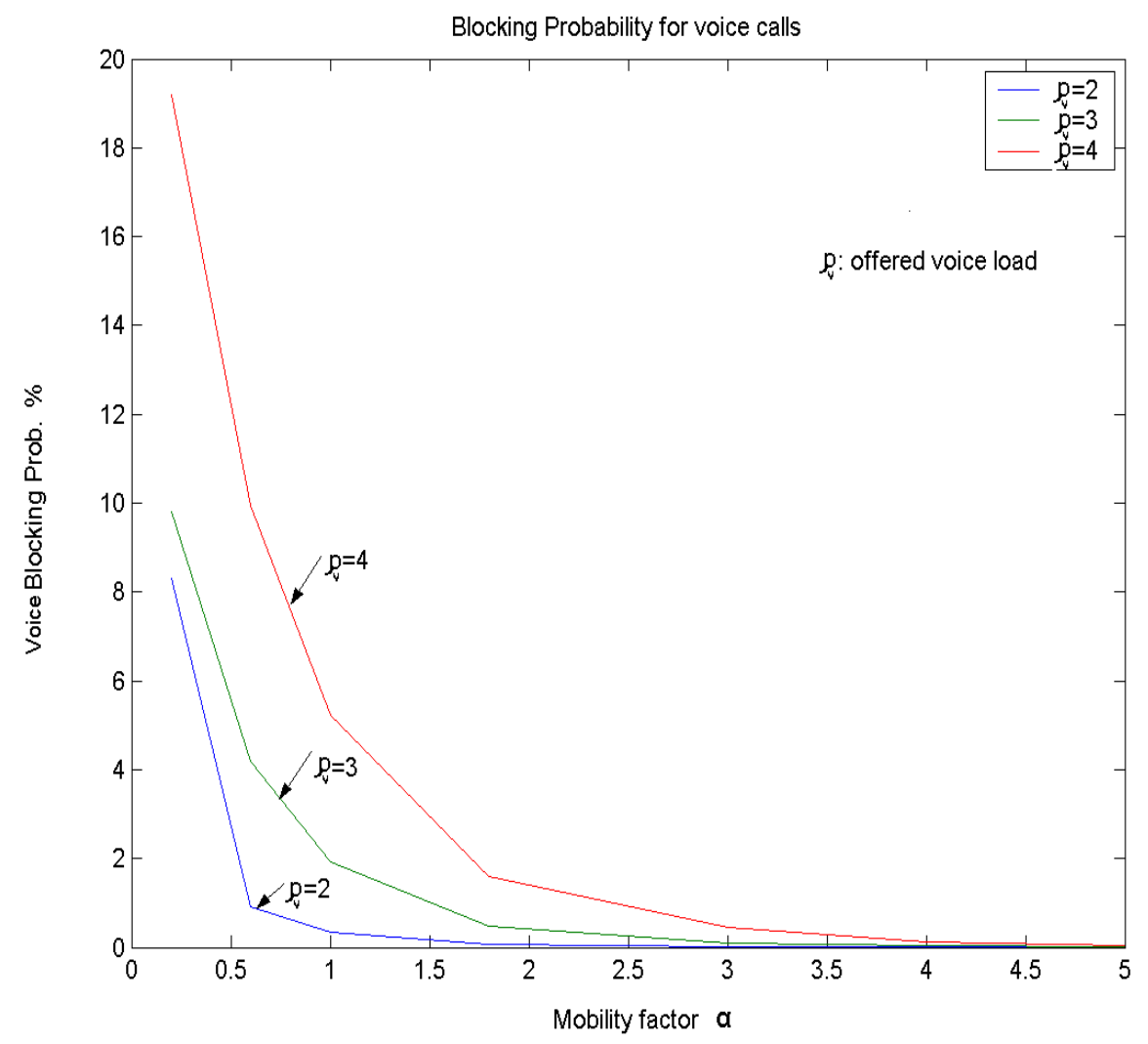

Fig. 2: Blocking probability for voice calls in GPRS Network.

As can be seen in figure 2, the blocking probability decreases dramatically with increasing the mobility factor and as expected, it also increases by increasing the offered voice load $\left(\rho_{\mathrm{v}}\right)$, where $\left(\rho_{\mathrm{v}}=\lambda^{\mathrm{v}} / \mu^{\mathrm{v}}\right)$.

We assume that the number of dedicated channels for the data service $d=1$ and the total number of channels per cell equal to 7 , also the impact of increasing the number of GPRS data dedicated channels on voice blocking probability can be studied from equation (3) as shown in figure 3 where we can see how the voice blocking probability increases with increasing the number of data dedicated channels (d).

For the short-term behavior of the system, [5] formulated the steady-state probability vector $\mathrm{q}_{\mathrm{k}}^{\mathrm{m}}$ as:

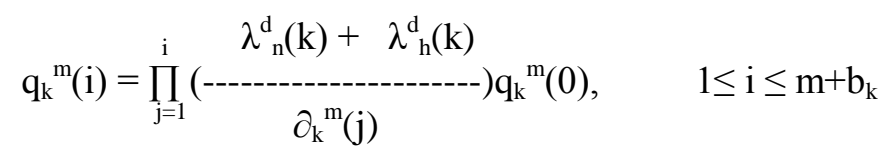

And using the normalization condition

$$
\sum_{\mathrm{i}=0}^{\mathrm{m}+\mathrm{b} k} \mathrm{q}_{\mathrm{k}}{ }^{\mathrm{m}}(\mathrm{i})=1
$$




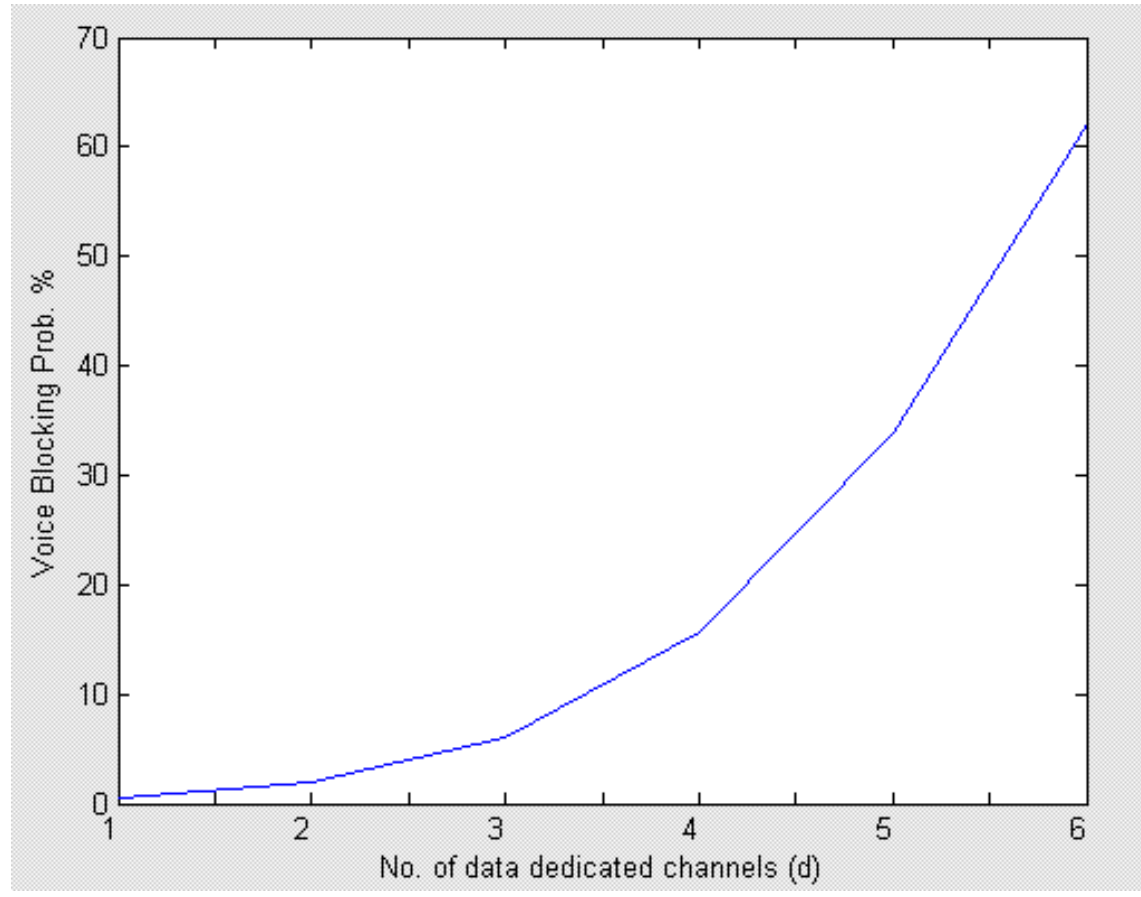

Fig. 3: Blocking probability for voice calls vs. number of data dedicated channels (d).

We simply get the value of $\mathrm{q}_{\mathrm{k}}{ }^{\mathrm{m}}(0)$ where the $\partial_{\mathrm{k}}{ }^{\mathrm{m}}(\mathrm{i})$ denote the transition rate from state $s_{i}$ to state $s_{i-1}$ when $\mathrm{m}$ channels serve the data packets, i.e.

$$
\partial_{k}{ }^{m}(i)= \begin{cases}i \mu_{k}{ }_{k} & 0 \leq i \leq m \\ m \mu_{k+(m-i)}^{d} \eta_{k}^{d} & m \leq i \leq m+b_{k}\end{cases}
$$

When the data packets do not find a free data channel to use the packets are forwarded to the buffer but in the case that the buffer is full, the packet will be lost so the packet loss probability can be given by

$$
\mathrm{L}_{\mathrm{m}}^{\mathrm{k}}=\mathrm{q}_{\mathrm{m}}^{\mathrm{k}}\left(\mathrm{m}+\mathrm{b}_{\mathrm{k}}\right)
$$

To obtain an approximate behavior for packet loss probability in the system, we aggregate the short-term behavior with respect to the long-term behavior [2], so the average loss probability in cell $\mathrm{k}$ can be given by

$$
\mathrm{L}_{\mathrm{k}}=\sum_{\mathrm{m}=\mathrm{d}_{\mathrm{k}}}^{\mathrm{c}_{\mathrm{k}}} \pi_{\mathrm{k}}(\mathrm{m}) \mathrm{L}_{\mathrm{k}}^{\mathrm{m}}
$$

From figure 4, it is shown that data packets loss probability increases with increasing the GPRS data load with a little dependence on the value of the mobility factor and this case results from the fact that the availability of free data channels decreases with the increase in the offered packet load then any new packets will be directed to the buffer till it reaches its maximum size and has no available slot for any new data packets, thus any new packets will be lost. 


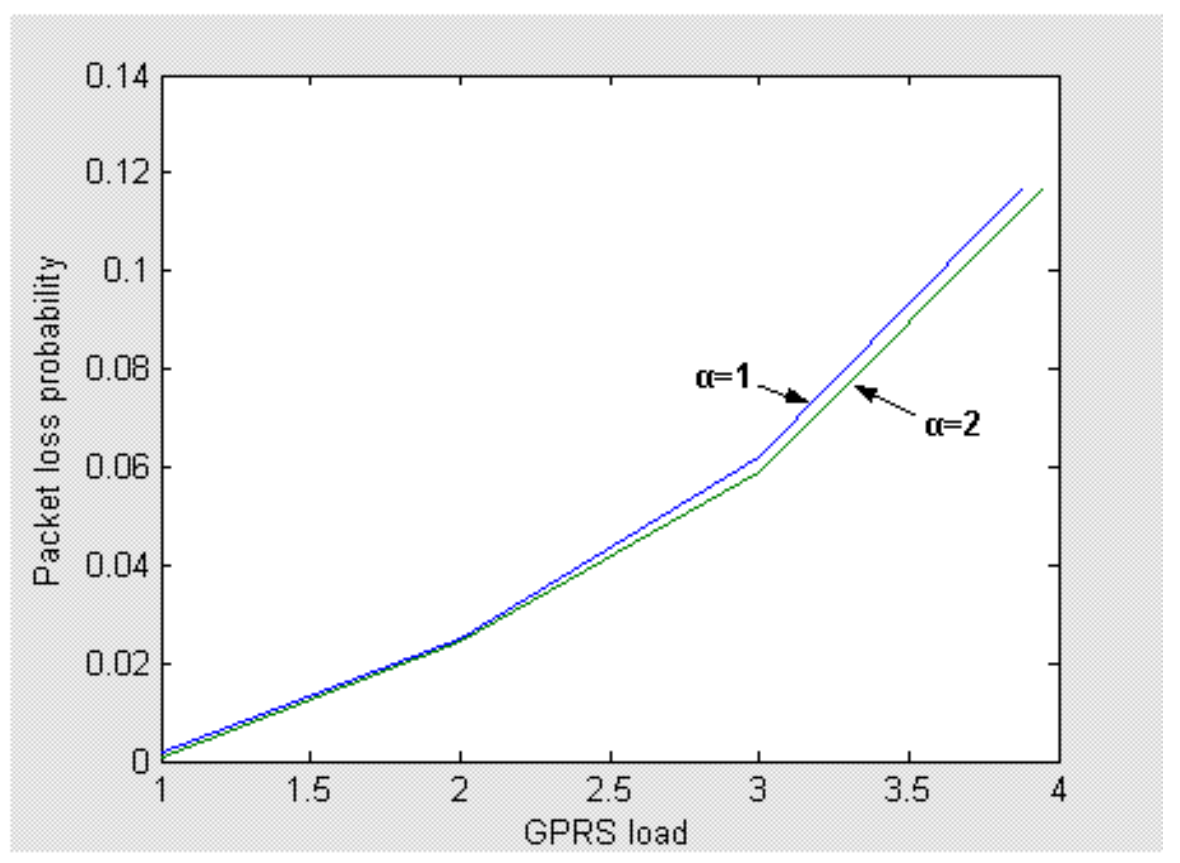

Fig. 4: Data packet loss probability vs the GPRS data load.

Now we check the effect of increasing the mobility factor on the packet loss probability. From figure 4 we can see that the packet loss decreases with increasing the mobility factor due to the dynamic behavior in the cell resources.

Regarding the third important parameter of the performance measurement keys which is the average packet delay, [2] formulated it in steady state as given below

$$
\mathrm{E}\left[\mathrm{W}_{\mathrm{k}}{ }^{\mathrm{m}}\right]=\sum_{\mathrm{i}=\mathrm{m}}^{\mathrm{m}+\mathrm{b}_{\mathrm{k}}-1} \mathrm{q}_{\mathrm{k}}^{\mathrm{m}(\mathrm{i}) \sum_{\mathrm{j}=\mathrm{m}}^{\mathrm{i}} 1 / \partial_{\mathrm{k}}{ }^{\mathrm{m}}(\mathrm{j})}
$$

The previous equation has been modeled to get the relation between the average steady state packet delay and the offered GPRS load $\rho$ for different values of the mobility factor $\alpha$.

The results that shown in figure $\mathbf{5}$ have been gotten by applying one carrier per cell so the total number of channels available in cell equal $7(\mathrm{c}=7)$ so if we dedicated one channel for the data $(\mathrm{d}=1)$ and the other for voice also we assume that $\mu^{\mathrm{d}}=5.5$, $\eta^{\mathrm{d}}=5.5 \& 11 \quad(\alpha=1 \& 2), \lambda_{\mathrm{h}}^{\mathrm{d}}=1.1 \& \mathrm{~b}=20$. Regarding GPRS offered load we take small value in the below figure $(\rho \mathrm{d}=1.1 / 5.5=0.2)$.

We took small value for $\lambda_{h}^{\mathrm{d}}$ that is smaller than $\lambda_{\mathrm{n}}^{\mathrm{d}}$ and also we took suitable value for the buffer size as we should compromise between large buffer size that may cause unacceptable queuing time and between small buffer size that cause very high loss probability. 
As can be seen from figure 5 , the average packet delay increases by increasing the offered GPRS load due to the increase in the waiting time inside the buffer where this delay decreases by increasing the mobility factor, also we should remember that the approximation implemented to get the above equations assumes small values of handoff rates with respect to the average data packet transmission time otherwise this approximation will not be valid. So we take small values of handoff rate $\lambda_{\mathrm{h}}$ with respect to the new data packets arrival rate $\lambda_{\mathrm{n}}$ and assume it to be constant value in our model.

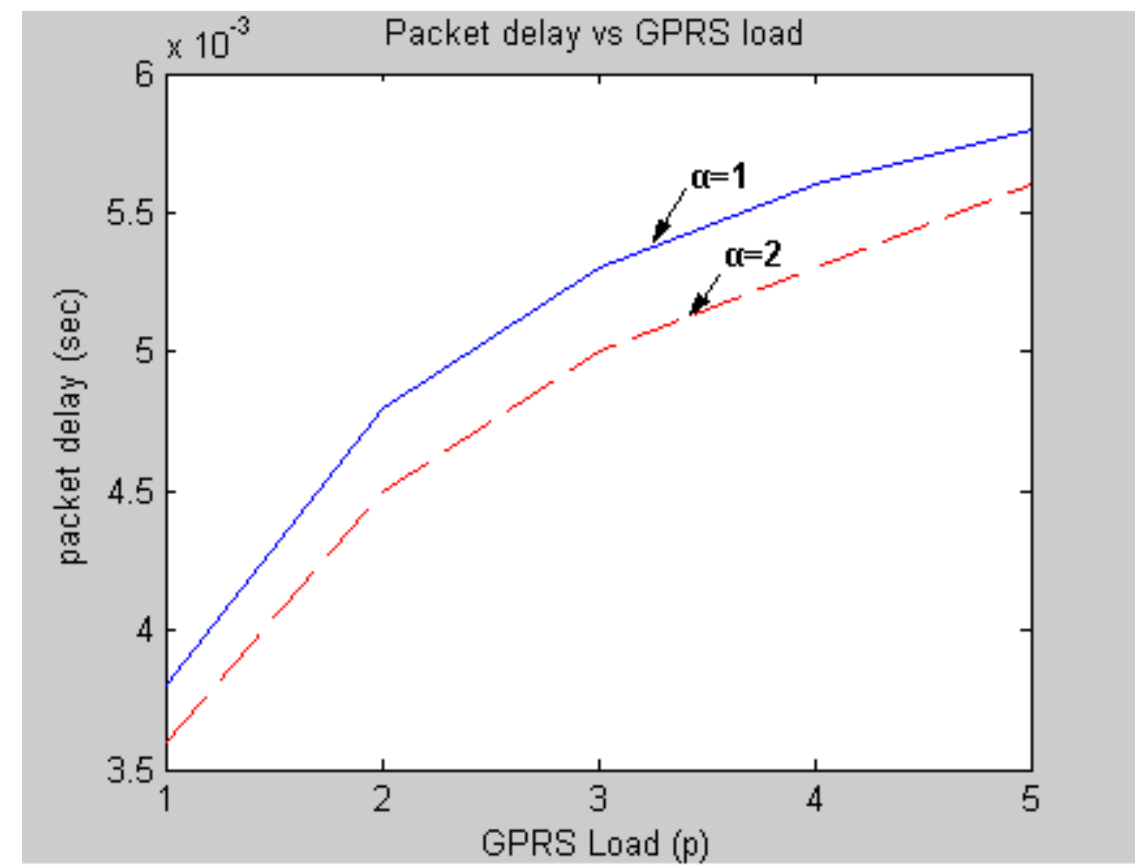

Fig. 5: The steady state average packet delay vs the GPRS load.

\section{CONCLUSIONS}

In this paper, we used a MATLAB program to obtain the numerical results of voice blocking probability, packet loss probability \& average packet delay of the GSM/GPRS analytical model that suggested in $[2,5]$ which uses the quasi-stationary behavior of data packet queuing process to decompose the system behavior into shortterm and long-term behaviors to simplify the analysis.

We show how the voice blocking probability decreases with increasing the mobility factor and also we show how the blocking probability increases with increasing the offered voice load.

Then we check the packet loss probability and check how it increase by increasing the GPRS load for the same buffer size as in specific instant if the packet does not find any free channel and the buffer was full, the packet will be lost and of course this case most probably occurs with high data packet load. 
We also check the effect of increasing the offered GPRS load on the packet delay parameter and how it causes the delay to increase in a dramatically way where the delay decrease by increasing the mobility factor of the system under consideration.

Finally, we can conclude that GPRS services in GSM network has a significant impact on the main service which is the voice service specially with increasing the data load till we reach a point where the blocking for the voice services exceed the accepted limits and also at this point the delay and the probability of data packet loss increase rapidly.

\section{REFERENCES}

[1] H. Wu, L. Li, B. Li, L. Yin and I. Chlamtac, "On handoff performance for an integrated voice/data cellular system," in Proc. IEEE PIMRC'02, vol. 5, Lisboa, Portugal, Sept. 2002, pp. 2180-2184.

[2] M.Ghaderi and R.Boutaba, "Data service performance analysis in GPRS systems," School of computer science, university of Waterloo, tech. Report, CS-2004-08, Feb. 2004.

[3] C.Lindemann, A.Thummler, "Evaluating the GPRS radio interface for different quality of service profiles," In Proc. $12^{\text {th }}$ GI/ITG Fachtagung Kommunikation in Verteilten Systemen (KiVS), Hamburg, Germany, pp. 291-301, Feb. 2001

[4] Y.-R. Haung, Y.-B. Lin, and J.-M. Ho, "Performance analysis for voice/data integration on a finite-buffer mobile system," IEEE Trans. Veh. Technol., vol. 49, no. 2, pp. 367-378, Mar. 2000.

[5] M.Ghaderi and R.Boutaba, "Mobility Impact on Data Service Performance in GPRS Systems," school of computer science, university of Waterloo, tech. Report, CS-2004-08, Feb. 2004. 


\section{دراسة تأثير الحركة و التنقل وزيادة الحمل على كفاعة

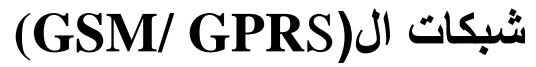

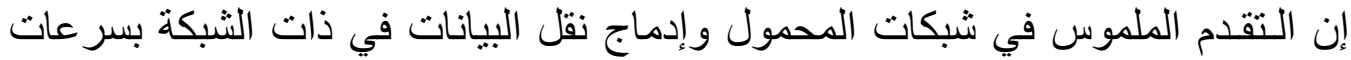
عالية تحت ما يسمى بشبكات (GPRS) كان مصحوبا بدر اسات عديدة للعو امل المؤثرة في كفاءة هذه الشبكات.

وفى هذا البحث نتعرض لنموذج تحليلي لاراسة الحركة و التنقل لوحدات أجهزة

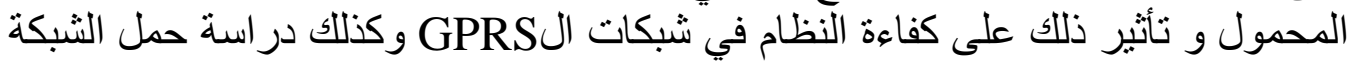

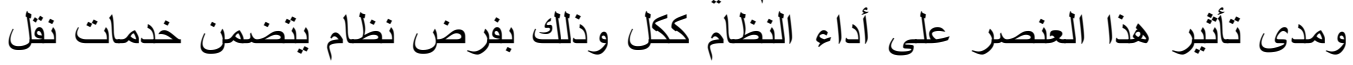

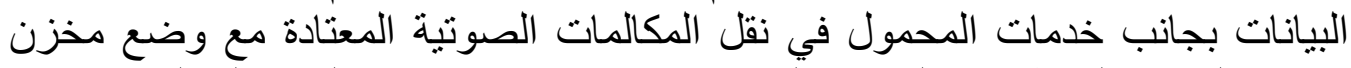

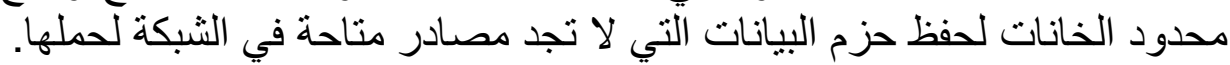

ومن خلال وضع نموذج رياضي لتوصيف كفاءة النظام بشكل تقريبي تم رسم بعض

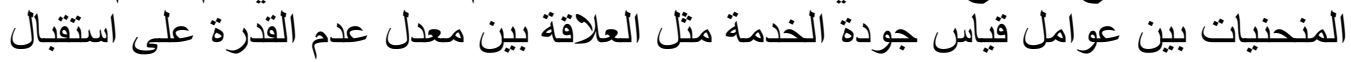

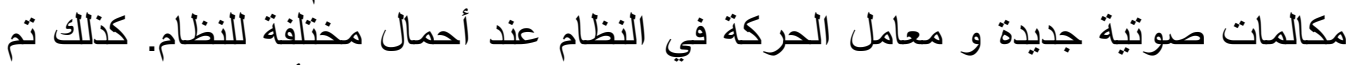

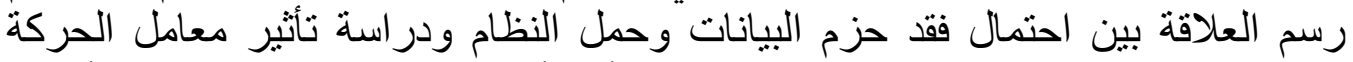

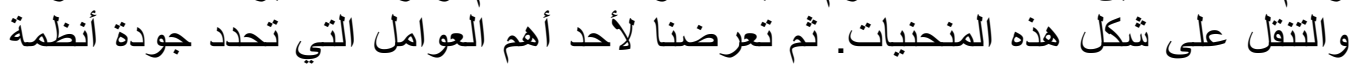

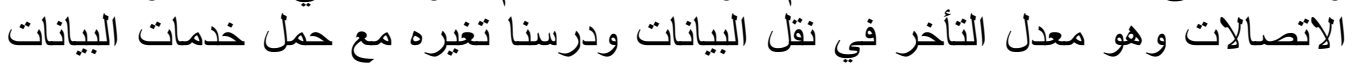

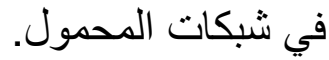
و اخير آ نذكر الاستتناج الذي خرجنا به من هذا البحث متضمناّ النتائج التي تم الحصول عليها. 